\title{
NEWS
}

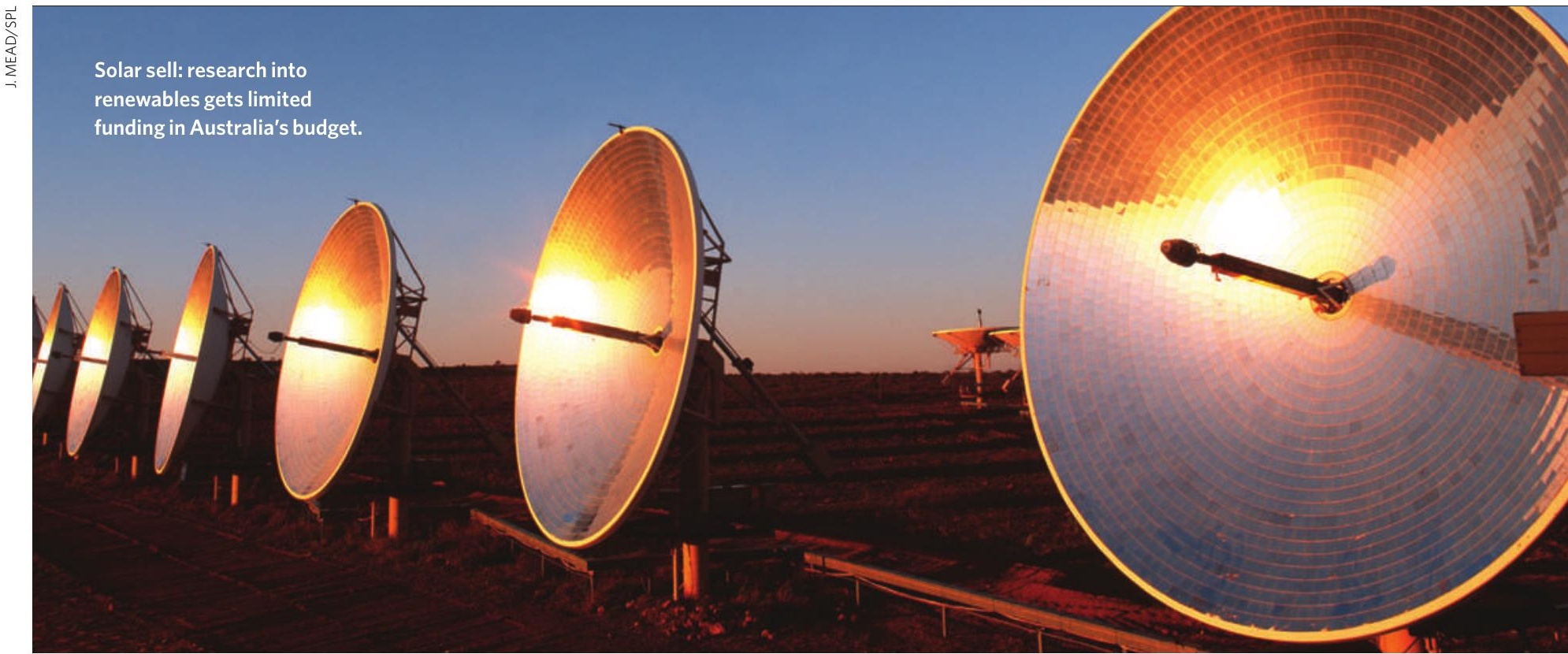

\section{Sunny outlook for Australian science}

\section{Research programmes win big in budget, but critics say environment is 'overlooked'.}

\section{SYDNEY}

An unexpected funding boost has left many Australian scientists in a positive frame of mind after federal treasurer Wayne Swan delivered a budget last week that raised research and education expenditure by almost $25 \%$ over the previous year's spending (see graph).

The budget, presented to parliament on 12 May, features a raft of research-related spending measures, including funding reform for universities and an overhaul of tax arrangements for private-sector research and development $(\mathrm{R} \& \mathrm{D})$ that had been recommended by recent government reviews of innovation and higher education. The budget numbers still need to be passed by the Senate.

Altogether, the proposed funding measures are worth Aus $\$ 5.7$ billion (US $\$ 4.3$ billion) over four years, including Aus $\$ 3.1$ billion on $\mathrm{R} \& \mathrm{D}$, with the remainder on education. "In the lead-up to the budget, the government talked down expectations," says John Quiggin, an economist at the University of Queensland in St Lucia. "But the budget outcome is far better than might have been feared in the light of pre-budget softening up."

The 25\% increase from 2008-09 to 2009-10 would represent the highest annual rise since records of science funding began in the 1970s, says Ken Baldwin, president of the Federation of Australian Scientific and Technological

\section{SCIENCE AND INNOVATION FUNDING IN AUSTRALIA}

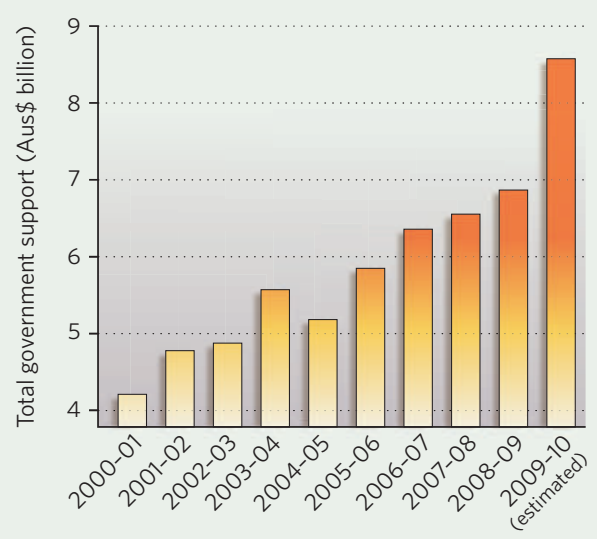

Societies, the main representative body for Australia's scientists. "I think this puts us back in the running with other countries that have invested significantly in science," he told Nature.

The investment is particularly significant given the current global financial downturn, Baldwin says. "Australia is relatively well placed in an economic sense, and is now relatively well placed in a research and development sense," he says. "It shows that the overall commitment to use research and development as a driver for economic recovery is front and centre of the government's planning."

A key measure is a phased commitment to fund the full cost of research in universities. Researchers have long complained about not getting enough funding to cover indirect research costs.

\section{Carbon concerns}

Not everyone was completely happy with the budget details. Some environmentalists, including prominent scientist and author Tim Flannery, have recently criticized Prime Minister Kevin Rudd's centreleft Labor government for failing to deliver on environmental promises, such as how a cap-and-trade programme to reduce carbon emissions might be implemented.

The budget does set aside Aus $\$ 4.5$ billion for clean-energy initiatives, including Aus $\$ 1.6$ billion for solar power. Still, Aus $\$ 2.4$ billion is earmarked for low-emissions coal technologies.

"What we got from the budget were some nice token gestures, but no policies that would allow a roll-out of renewable energy on a large scale," says Mark Diesendorf, an environmental scientist from the University of New South Wales in Sydney. "The problem is that the coal industry and some of the other big greenhouse polluters have enormous political influence in Australia," he says. "The federal government has actually rejected implementing policies that would drive large-scale solar and other large-scale renewable-energy technologies that have enormous potential." 
Yet for most researchers, the increased spending was welcome. For the CSIRO, Australia's national science agency, the budget offered an increase in direct funding of Aus $\$ 43$ million, or $6.3 \%$, in the next financial year. The agency will also gain Aus $\$ 120$ million to deliver a new marine-research vessel by 2012 , and Aus $\$ 30$ million to expand its Living Atlas of Australia, an integrated system for managing the country's biodiversity data.

CSIRO chief executive Megan Clark says that, among other things, the budget increases will boost research into agricultural productivity.

In astronomy, the budget promises Aus $\$ 80$ million to support Australia's bid to host the Square Kilometre Array, a Aus $\$ 3$-billion radiotelescope project for which it is competing with South Africa. It also includes Aus $\$ 20.9$ million to help Australia take sole responsibility for the Anglo-Australian Observatory when the United Kingdom withdraws its involvement next year, and Aus $\$ 40$ million for an Australian space-research programme.

The private sector also gained from the budget, with biotechnology firms winning an item that was top of their wish list: reforms to taxation of R\&D. Michelle Gallaher, chief executive of the biotech industry group BioMelbourne Network, says that many in the sector would see the benefits of the announced tax credits, worth an estimated Aus $\$ 1.4$ billion per year. "The budget certainly was better than our expectations," she says.

In medical research, cancer specialists were particularly pleased by news that the government may spend Aus $\$ 560$ million to build a network of regional cancer centres. Patients treated in those centres would be well situated to participate in clinical trials, says Ian Olver, chief executive of the Cancer Council Australia.

Despite the positive mood, some researchers, such as Robert Graham, president of the Association of Australian Medical Research Institutes, are already warning that big gains may not be sustainable in future years.

"Now that we're finally in the running in the biomedical science and biotechnology industry," he says, "we look to the Rudd government to ensure that in the future we are not relegated back to a high chair."

Stephen Pincock

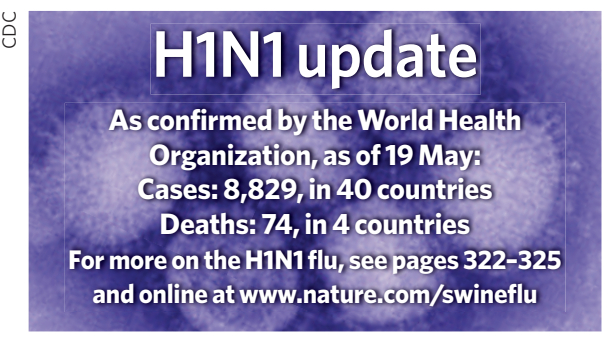

\section{Public donations to lift research}

Researchers looking for a little extra money to explore an idea may soon have a new funding 'agency' to ask for help: the masses. A Florida researcher has launched a project designed both to solicit public donations for individual research programmes and to inspire public interest in science and engineering.

The 'SciFlies' project (www.sciflies. org) will profile scientists from a range of disciplines and the new ideas they want to pursue, or ways in which they would like to expand their current research programme. Website visitors will be able to donate any amount to support the projects they find most interesting or worthwhile.

David Fries, a marine engineer at the University of South Florida in St Petersburg, conceived of and heads the SciFlies effort. His main inspiration was long-standing frustration with a research funding structure that, with few exceptions, offers scientists no intermediate steps on the way to requesting full grant funding. So last year he joined forces

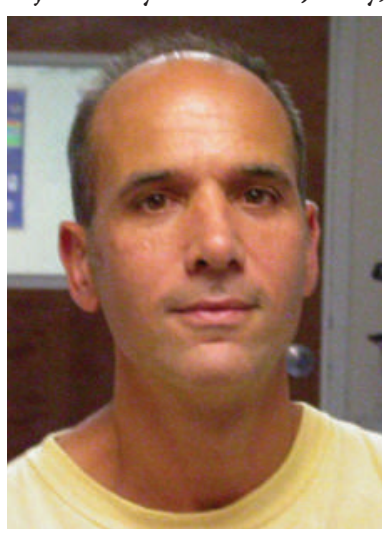

David Fries: hoping his concept of grass-roots funding will fly. their overall research vision, past accomplishments, interests and even what they are currently reading. The hope is to inspire genuine and long-term interest in researchers, who will be required to post regular updates on their work, and science in general.

For now, the team plans to profile every scientist who signs on. Anyone who doesn't bring in donations or keep their profile updated is likely to be culled from the list.

Oscar Schofield, an oceanographer at Rutgers University in New Brunswick, New Jersey, will be one of the first scientists to be profiled. By using tools such as robotic gliders, his group gathers data, including ocean temperature and salinity, that are used regularly by the public. But in the past he has had to turn down offers by users to donate to his programme because of the difficulty of processing small donations. "What's brilliant about SciFlies is not only its ability to reach people, but how it will provide a mechanism where those little contributions build with Larry Biddle, a political and nonprofit fund-raiser who helped to pioneer Internet-donations campaigns for Howard Dean's 2004 presidential run, and Michelle Bauer, founder and chief strategist of Common Language, a communications firm based in St Petersburg.

\section{Pretty fly for a sci guy}

Fries hopes that SciFlies will be a way for scientists around the world to secure funding in the US\$5,000-10,000 range. Such funding can be enough, for instance, to hire a graduate student to run initial experiments that might determine if an idea is worthy of a grant proposal.

Fries says the name SciFlies has a triple meaning. It's a homage to the ubiquitous fruitfly research model, a shorthand description of the goal to create a 'swarm' of science supporters, and a reference to 'fly', a slang term for cool.

The site will profile research projects and the scientists themselves, including up and then get delivered at some later point," he says.

SciFlies will distribute cheques to researchers after their donations reach $\$ 5,000$. Anyone who doesn't make that amount will not get any money, and donors will be asked to redesignate their money.

Rush Holt (Democrat, New Jersey), a physicist and member of the US House of Representatives, sees the SciFlies concept as akin to public funding of the arts, and a potential way to boost research in line with increases proposed by the administration of US President Barack Obama. "It's an innovative approach that I think we should be encouraging," says Holt.

An initial SciFlies website, aimed at getting researchers to sign on for profiling, launched on 15 May. The full site, ready for donations, will be launched in July. Mark Schrope 